\title{
As elasticidades setoriais das exportações brasileiras: uma análise empírica para o período 1999-2013
}

The sector elasticities of Brazilian exports: an empirical analysis for the period 1999-2013

\author{
Dieison Lenon Casagrande (1) \\ Paulo Ricardo Feistel (2) \\ Álvaro Barrantes Hidalgo(3) \\ André Filipe Zago de Azevedo (4)
}

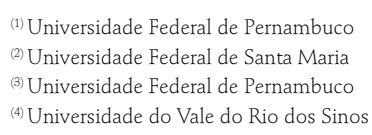

(4) Universidade do Vale do Rio dos Sinos

\section{Abstract}

The objective of this study is to analyze the performance of Brazilian exports of primary commodities and manufactures for the Asian, NAFTA, European Union and MERCOSUR countries between 1999 and 2013 From an extension of the Imperfect Substitutes Model, elaborated by Goldstein and Khan (1978), the Error Correction Model (ECM) was used to determine the short- and long-term elasticities. The results show that in the trade with these blocks of countries, commodities are more sensitive to external income than to other variables considered in this study. As for manufactures, the results also point to a greater influence of the variable income, except for the block of Asian countries, where the variable relative price seems to be the most important determinant and that exports of manufactured goods are more sensitive to changes in the exchange rate than exports of primary commodities.

\section{Keywords}

Sector elasticities; Exports; Brazil.

JEL Codes F113; F14; F17.

\section{Resumo}

O objetivo deste estudo é analisar o desempenho das exportações brasileiras de produtos básicos e manufaturados para os blocos de países da Ásia, do NAFTA (Tratado Norte-Americano de Livre Comércio), da União Europeia e do Mercosul (Mercado Comum do Sul) entre os anos de 1999 e 2013. A partir do Modelo de Substitutos Imperfeitos de Goldstein e Khan (1978), foi utilizado - Modelo de Correção de Erros (ECM) para a determinação das elasticidades de curto e de longo prazo. Os resultados obtidos apontam que no comércio com esses blocos de países os produtos básicos são mais sensiveis à renda externa do que para as outras variáveis consideradas. Quanto aos produtos manufaturados, os resultados apontam maior sensibilização à variável renda, exceto para o bloco de países da Ásia, onde a variável preço relativo parece ser o determinante mais importante e que as suas exportações são mais sensiveis a mudanças na taxa de câmbio do que as exportações de produtos básicos.

\section{Palavras-chave}

Elasticidades setoriais; Exportações; Brasil.

Códigos JEL F113; F14; F17. 


\section{Introdução}

As exportações, como um componente do Produto Interno Bruto (PIB), são um importante indicador macroeconômico. No atual contexto do mundo globalizado, é praticamente impossível um país crescer e se desenvolver produzindo apenas para o mercado doméstico.

Nas últimas décadas, as exportações brasileiras apresentaram crescimento significativo e mudança não apenas na direção dos fluxos comerciais, mas também na composição da pauta. Segundo dados do Ministério do Desenvolvimento Indústria e Comércio/Secretaria de Comércio Exterior (MDIC/SECEX), durante o período 1999-2013, as exportações do Brasil apresentaram crescimento médio anual de $14,4 \% .^{1}$ Entre os principais destinos das exportações brasileiras, destacam-se a Ásia (sendo a China o principal parceiro), o Mercosul (tendo a Argentina como principal parceiro), o NAFTA (tendo os Estados Unidos principal parceiro) e a União Europeia.

A partir de 1999, os dados do (MDIC/SECEX) mostram que a participação média dos referidos parceiros comerciais nas exportações brasileiras girou em torno de 76,5\% - ao analisar-se pela ótica da receita - enquanto, em quantum, essa participação gira em torno de 90,0\%. Houve, porém, nesse período, uma mudança na direção dos fluxos comerciais. Em particular, destaca-se a significativa redução da participação do NAFTA e da União Europeia, com queda na representatividade de $24,4 \%$ e $27,9 \%$, em 1999, para $12,8 \%$ e $19,0 \%$, em 2012 , respectivamente. Da mesma forma, a participação das exportações para o Mercosul caiu de 14,4\% em 1999 para $11,9 \%$ em 2012. Por outro lado, a participação dos países da Ásia nas exportações brasileiras aumentou, passando de 11,8\% em 1999 para $31,1 \%$ em 2012.

Ao analisar-se a composição da pauta de exportações brasileiras por fator agregado, segundo os dados do (MDIC/SECEX), verifica-se acentuado declínio da participação de produtos manufaturados. Com representatividade em torno de 47,0\% em 1999, o setor representou apenas 30,3\% em 2012. Em contrapartida, a participação de produtos básicos mais que

1 Entretanto, desde o início de 2013, o comércio exterior brasileiro tem apresentado dificuldades de crescimento, devido, em grande parte, à crise do sistema financeiro internacional ao final da última década, ao baixo crescimento da demanda internacional e à concorrência acirrada presente nos mercados que ainda apresentam crescimento econômico. 
dobrou nesse período, saltando de $19,3 \%$ no início da série para $40,4 \%$ ao final. Já os produtos semimanufaturados continuaram com participação constante, em torno de 30,0\% durante o período. Quanto aos produtos exportados, temos que os principais produtos básicos da pauta de exportações são soja em grão, minério de ferro e petróleo bruto. No que se refere aos semimanufaturados, os principais produtos são açúcar bruto, celulose e semimanufaturados de ferro/aço. Por fim, os principais produtos manufaturados exportados são automóveis de passageiros, plataforma para extração de petróleo e autopeças.

O comportamento dos fluxos comerciais tem efeitos sobre a economia, sendo sua dinâmica seguida de perto pelos analistas de mercados e pelos formuladores de políticas econômicas. $O$ conhecimento do grau de inter-relacionamento comercial com seus pares é importante para os formuladores de políticas, que optam entre a adoção da política comercial e/ou opções de desvalorização da taxa de câmbio, a fim de melhor estruturar o comércio exterior. Dada a dinâmica das exportações brasileiras, cabe o desafio de identificar qual a sensibilidade dos produtos de exportação em relação a mudanças em variáveis condicionantes do comércio internacional, tais como o nível de renda real externa, o preço dos bens exportados e a taxa de câmbio real, e quais dessas variáveis são mais importantes na explicação dessas relações.

As evidências mostram que existem diferenças de comportamento do quantum exportado dos setores diante de mudanças nas variáveis macroeconômicas internacionais. Essas relações foram verificadas através da análise das elasticidades. A estimação de elasticidades do comércio exterior brasileiro é assunto longamente estudado na literatura nacional, sendo que os resultados quanto aos valores dessas elasticidades nem sempre se apresentam consensuais. ${ }^{2}$

Recentemente, Kawamoto, Santana e Fonseca (2013) estimaram elasticidades renda e preço das exportações e importações de produtos industrializados no Brasil para o período 2003-2010. Os autores estimaram modelos estáticos e dinâmicos utilizando o método do estimador para cor-

2 Alguns dos trabalhos para os produtos manufaturados na economia brasileira são: Pinto (1980), Cardoso e Dornbusch (1980), Braga e Markwald (1983), Zini (1988), Portugal (1993), Castro e Cavalcanti (1997), Cavalcanti e Ribeiro (1998), Ferreira (1998) e Castilho (2009). Por sua vez, Barros, Bacchi e Burnquist (2002), Carvalho e De Negri (2000), Mortatti, Miranda e Bacchi (2011) e Feistel, Hidalgo e Zuchetto (2015), analisam o comércio de produtos agropecuários. 
reção de viés em painéis dinâmicos com pequeno número de indivíduos. Segundo os autores, as exportações e importações de produtos industriais se mostraram mais sensíveis a mudanças na renda que a variações nos preços. Além disso, os autores encontram resultados não intuitivos no que se refere ao efeito da taxa de câmbio sobre exportações, na qual o câmbio parece ter efeito negativo na demanda de exportações.

Por outro lado, Castilho e Luporini (2009) estimam elasticidades-renda das exportações setoriais brasileiras para os principais parceiros comerciais, no período 1986-2007. Para calcular as elasticidades, as autoras estimaram um modelo uniequacional via cointegração e modelo de defasagens distribuídas. Os resultados obtidos indicam que os produtos minerais são pouco sensíveis a variações na renda (elasticidades-renda inferiores a $1 \%)$, enquanto os produtos agrícolas e manufaturados apresentam elasticidades bastante elevadas.

Meyer (2008) realizou estimativas para o período 1999-2006 utilizando dois modelos: modelo simultâneo de oferta e demanda de exportações e modelo de cointegração de Engle e Granger. Nos dois casos, as exportações foram desagregadas em manufaturados, semimanufaturados e básicos. As estimativas com ambos os métodos, tanto no longo como no curto prazo, mostraram que o aumento dos preços dos produtos exportados, assim como o aumento da renda mundial, foi importante para o crescimento das exportações. No que se refere à oferta de exportação, a utilização de capacidade e os preços dos produtos exportados mostram-se correlacionados positivamente com o quantum ofertado, enquanto a taxa de câmbio apresentou elasticidades negativas.

Bonelli (2006) realizou estimativas de elasticidades de exportação para as empresas industriais brasileiras no período 1998-2003. As estimativas obtidas pelo autor mostram elasticidades-renda da demanda de exportações bastante elevadas, diferentemente das elasticidades-preço, que se apresentam relativamente menores. Segundo o autor, as elasticidades-preço parecem aumentar à medida que se afastam dos produtos mais próximos da base de recursos naturais, indo em direção aos mais sofisticados, de maior valor adicionado.

Ribeiro (2006), por outro lado, estimou elasticidades de demanda de exportações de longo prazo, encontrando que preços e renda parecem ter efeitos sobre as quantidades, sendo a última também relevante no curto prazo. Para o período analisado (1999-2005), houve evidência de que a 
demanda foi mais importante do que a oferta, com os efeitos da renda externa e dos preços de exportação sobrepondo-se aos da taxa de câmbio.

Pourchet (2003) analisou o impacto do câmbio sobre diversos setores de exportação do Brasil, com o modelo econométrico uniequacional. $O$ autor utilizou o modelo de defasagens autorregressivas distribuídas a fim de obter elasticidades de longo prazo. Os resultados das elasticidades-câmbio das exportações indicam uma relação de longo prazo na maior parte dos setores estudados, porém com baixo impacto. As elasticidades-câmbio estimadas são inferiores à unidade. Por outro lado, no curto prazo, o efeito da taxa de câmbio parece ser ainda menor. Assim, segundo o autor, as estimativas parecem mostrar que o câmbio tem pouco efeito sobre as exportações.

Em resumo, as evidências empíricas para o Brasil parecem mostrar elevadas elasticidades-renda da demanda de exportações, sendo maiores que as elasticidades-preço. Também, as elasticidades renda e preço diferem significativamente segundo os grupos de produtos considerados. Todavia, os resultados parecem mostrar baixa elasticidade da taxa de câmbio sobre as exportações, chegando a ser negativa em alguns casos. Este último resultado parece ser não intuitivo e estudos que procurem compreender melhor esse fenômeno são relevantes. Tendo em vista a variabilidade de resultados obtidos para as elasticidades do comércio exterior brasileiro, novas estimativas tornam-se importantes. Além disso, a literatura existente mostra pouco esforço de estimação de elasticidades de exportação setoriais em nível de principais parceiros comerciais do Brasil.

Assim, o objetivo deste trabalho é analisar o desempenho das exportações brasileiras e realizar novas estimativas das elasticidades preço, renda e taxa de câmbio para os produtos básicos e manufaturados. As novas elasticidades serão estimadas para o longo prazo e segundo os principais parceiros comerciais do Brasil: a Ásia e os Blocos Comerciais do NAFTA, Mercosul e União Europeia; o período considerado será de janeiro de 1999 a junho de 2013. Neste estudo, as inferências que serão realizadas acerca das elasticidades dar-se-ão através de um modelo uniequacional via cointegração de Johansen e pela modelagem do Mecanismo de Correção de Erros.

Para atender aos objetivos propostos, este estudo encontra-se dividido em quatro seções, além desta introdução. Na segunda seção, apresentam-se os aspectos teóricos e a especificação da função de exportações a ser estimada. A terceira seção contempla o processo de obtenção das variáveis, uma breve descrição de seu comportamento e os procedimentos me- 
todológicos de estimação da função de exportações. A quarta seção, por sua vez, apresenta os resultados, e a última seção apresenta as conclusões.

\section{Considerações teóricas e especificação do modelo}

O estudo das variáveis determinantes das exportações de um país pode ser feito analisando-se não apenas os fatores que determinam a demanda de exportações, mas também os fatores que determinam a oferta de exportações. Segundo Cavalcanti e Ribeiro (1998), a especificação de uma equação para as exportações está baseada em três hipóteses teóricas fundamentais. A primeira delas refere-se ao caso do país pequeno. Essa hipótese admite que as exportações do país que está sendo analisado representam uma pequena fração do comércio mundial. Assim, o país em questão é incapaz de afetar os preços internacionais do bem que está sendo analisado e a demanda de exportações desse bem seria perfeitamente elástica. Nesse caso, existiria apenas a possibilidade de estimação da função de oferta de exportações desse bem, e as variáveis determinantes seriam aquelas relacionadas à capacidade ou disposição dos produtores em produzir e exportar esse produto. Entre as variáveis determinantes da oferta de exportações, cabe destacar a capacidade produtiva do setor exportador, a rentabilidade real do exportador e o nível de demanda doméstica.

A segunda hipótese elencada para o modelo de exportações admite que estas representem uma fração significativa do mercado, ou ainda que os produtos sejam diferenciados no mercado internacional. Nesse caso, admite-se uma demanda de exportações com elasticidade-preço finita. Postulando-se que existe capacidade ociosa na indústria e oferta de exportação perfeitamente elástica (ou uma tecnologia com rendimentos não decrescentes de escala), pode-se estimar somente a função de demanda de exportações.

A premissa de bens substitutos imperfeitos garante que a elasticidade- preço da demanda de exportações seja finita, permitindo sua estimação empírica. Os determinantes da demanda de exportações seriam basicamente a renda real internacional, relacionada ao consumo dos bens demandados no exterior, e os preços relativos, representando a importância relativa do preço dos bens domésticos em relação ao preço dos bens substitutos no estrangeiro. 
A terceira hipótese teórica sobre o modelo de exportações considera tanto os elementos da demanda de exportações quanto da oferta de exportações; nesse caso, admite-se que as elasticidades-preço de ambas as funções são finitas. Como de costume, os preços e as quantidades de equilíbrio são determinados pela interação das funções de demanda e de oferta de exportações. ${ }^{3}$

$\mathrm{Na}$ literatura brasileira, as primeiras pesquisas sobre os determinantes das exportações admitiam a premissa de país pequeno e estimava-se basicamente a função de oferta de exportações. ${ }^{4}$ Dada a pauta de exportações brasileira daquela época, essa premissa parecia aceitável. Com efeito, as exportações do Brasil estavam concentradas em produtos primários e semimanufaturados, relativamente homogêneos, e o país detinha participação relativamente pequena no mercado internacional.

A partir de então, com o avanço da exportação de produtos manufaturados, os estudos sobre as exportações brasileiras começaram a considerar a hipótese de substitutos imperfeitos e os modelos estimados passaram a admitir que preços e quantidades de exportações sejam determinados pela interação da oferta e demanda de exportações, sendo a elasticidade-preço finita; ver, por exemplo: Pinto (1980) e Braga e Markwald (1983). A determinação simultânea do preço e da quantidade exportada significava que as funções de oferta e demanda de exportações fossem estimadas seja na forma estrutural ou na forma reduzida. ${ }^{5}$ Apesar do progresso metodológico realizado nesses trabalhos para estimar as equações sobre comércio no Brasil, a validade das equações estruturais especificadas não foi verificada empiricamente.

Posteriormente, Cavalcanti e Ribeiro (1998) realizaram estimativas de equações de exportação para o Brasil, apresentando testes sobre a especificação dessas equações. Por outro lado, aproveitando desenvolvimentos recentes da econometria, Castro e Cavalcanti (1997) estimam equações de exportação e importação, atentando para a não estacionariedade das variáveis, utilizando o conceito de cointegração e o modelo de correção de erros, além de realizar testes de exogeneidade para as variáveis exógenas.

Conforme mencionado, esforços adicionais foram realizados na literatura brasileira a fim de utilizar novas técnicas econométricas na estimação das 3 Ver Goldstein; Khan (1978).

4 Ver Cardoso; Dornbusch (1980).

5 Ver Zini (1988; Portugal (1993). 
elasticidades comerciais, na estimação de elasticidades a nível setorial ${ }^{6}$ e na estimação da elasticidade da taxa de câmbio. ${ }^{7}$ Dessa forma, o conjunto de modelos utilizados para estudar o comportamento das exportações brasileiras vem crescendo, incorporando cada vez mais os avanços na econometria.

Em contraste, conforme foi apontado anteriormente, as exportações do Brasil vêm mudando em sua estrutura, aumentando a participação relativa de alguns produtos básicos, tais como minério de ferro, soja, açúcar, café e outros primários. Dada a participação brasileira no mercado internacional desses produtos, o país parece possuir algum grau de poder de mercado, evidenciado através de diferenças entre os preços praticados no país e no estrangeiro. Assim, tornou-se comum na literatura a adoção da hipótese de substitutos imperfeitos para os produtos exportados pelo Brasil, mesmo para aqueles que, em princípio, são considerados como homogêneos.

Portanto, neste artigo utilizar-se-á a hipótese de exportação de bens substitutos imperfeitos, e um modelo uniequacional será estimado para as exportações, incluindo fatores tanto da demanda quanto da oferta de exportações. À função de exportações somam-se a variável taxa de câmbio real e a volatilidade cambial. ${ }^{8}$ Assume-se, dessa forma, a seguinte relação funcional para as exportações:

$$
X=f\left(P R, Y^{*}, T C, V\right)
$$

onde: $X$ representa o quantum das exportações; $P R$ representa o índice de preços relativos, uma razão entre o preço dos bens exportados pelo país e os preços dos bens concorrentes produzidos no resto do mundo; $Y^{*}$ uma medida da renda mundial; $T C$ a taxa de câmbio real efetiva; e $V$ uma medida da volatilidade cambial.

Quanto aos sinais esperados para as variáveis especificadas, infere-se que, a priori, o nível de exportações é negativamente relacionado com os preços relativos. Isto ocorre porque os consumidores estrangeiros substituem o bem exportado quando o seu preço se eleva em relação aos produtos concorrentes; aumento no nível de renda dos parceiros comerciais impacta de forma positiva o aumento das exportações. 
$\mathrm{Na}$ demanda por importações do resto do mundo por produtos originados no país $i$, uma desvalorização da taxa de câmbio real torna os produtos do país $i$ mais baratos frente aos seus similares estrangeiros, proporcionando aumento nas quantidades demandadas. Ainda, na demanda no mercado internacional, a volatilidade da taxa de câmbio pode impactar negativamente a demanda por exportações do país $i$.

Segundo Ribeiro (2006), o comércio exterior fundamenta-se fortemente na construção de relações de confiança entre as partes, as quais são de longo prazo, e não há motivos para a troca de parceiros comerciais de período em período. A volatilidade cambial é uma medida de prevenção dos importadores frente a possíveis alterações em seus custos; a alta volatilidade faz o importador buscar novos fornecedores com menores variações de preços. Assim, um aumento da volatilidade pode levar a uma diminuição da demanda por exportações do país $i$.

\section{Dados, comportamento das variáveis e aspectos metodológicos}

\subsection{Descrição dos dados}

Os dados utilizados têm periodicidade mensal, de janeiro de 1999 a junho de 2013, resultando num total de 174 observações. A variável dependente para cada um dos modelos estimados corresponde ao índice de quantum das exportações $(X)$ brasileiras do setor $i$ para o destino $j$, em que $i \in$ (Básicos,Manufaturados) e $j \in$ (Ásia,Nafta,União Europeia,Mercosul), expressa na forma logarítmica, que se baseia na metodologia utilizada pela Funcex (Fundação Centro de Estudos de Comércio Exterior) para o cálculo dos índices agregados. ${ }^{9}$ Os dados utilizados pela Funcex provêm da Secretaria de Comércio Exterior (SECEX/MDIC), com valores FOB (Free on Board) correntes.

O índice de preços relativos é dado pela relação $\left(P_{x} / P_{w}\right)$, onde $P_{x}$ representa o preço das exportações brasileiras do setor $i$ para o destino $j$

9 De acordo com a metodologia adotada pela Funcex, que é baseada em Guimarães et al. (1997), os principais produtos exportados por classes de produtos, que são divididos em: básicos (68); semimanufaturados (36); manufaturados (305); transações especiais (2); consumo a bordo (2); reexportação (1). 
e $P_{w}$ representa o preço dos competidores no mercado internacional. As séries que representam o preço das exportações, separadas por fator agregado, foram elaboradas conforme metodologia proposta por Guimarães et al. (1997) e esse nível de preços pode ser considerado como intrassetorial (Ribeiro, 2006).

A metodologia adotada por Guimarães et al. (1997) para o Índice de Preço é determinada a partir do Índice de Fisher (que consiste na multiplicação entre o Índice de Preços de Laspeyres e o Índice de Preços de Paasche), em que os preços de um período são comparados com os de um período-base:

$$
I_{P}^{0,1}=\sqrt{\left.\left.\left[\left(\sum p_{i}^{1} \cdot x_{i}^{0}\right) / \sum p_{i}^{0} \cdot x_{i}^{0}\right)\right] \cdot\left[\left(\sum p_{i}^{1} \cdot x_{i}^{1}\right) / \sum p_{i}^{0} \cdot x_{i}^{1}\right)\right]}
$$

onde: $p_{i}^{0}$ é o preço da mercadoria $i$ no período-base; $p_{i}^{1}$ é o preço da mercadoria $i$ no período subsequente; $x_{i}^{0}$ é a quantidade da mercadoria $i$ no período-base; e $x_{i}^{1}$ é a quantidade da mercadoria $i$ no período subsequente. De forma implícita, o índice de quantum é calculado deflacionando-se a série de valor $\mathrm{FOB}$ da exportação pelo índice de preço, ou seja:

$$
I_{q}^{0,1}=\left(v^{1} / v^{0}\right) / I_{P}^{0,1}
$$

onde: $v^{1}$ é o valor das exportações FOB no período subsequente; e $v^{0}$ é o valor das exportações FOB no período-base..$^{10}$

Como proxy do índice de preços dos concorrentes estrangeiros de produtos básicos, utiliza-se o índice de preços das commodities, extraídos do International Financial Statistics (IFS), já para os produtos manufaturados, utiliza-se o índice de preços das exportações dos Estados Unidos, disponível na base de dados do Bureau of Labor Statistics. ${ }^{11}$ A importância de levar em consideração uma variável de preços relativos reside no fato de que os parceiros comerciais observam o comportamento de preços no mercado internacional.

Para mensurar a capacidade de absorção do bloco de destino - renda externa -, utilizou-se o valor total das importações dos principais o índice de preços das importações dos países industrializados, fornecido pelo International Monetary Fund/International Financial Statistics (FMI/IFS). 
parceiros comerciais, tal qual Castro e Cavalcanti (1997), obtida junto ao sistema de dados das Nações Unidas, UN Comtrade e International Financial Statistics (IFS), ponderada pela participação de cada país nas exportações brasileiras. Essa variável consiste em uma proxy de absorção de comércio, variável relevante para a avaliação dos fluxos comerciais feita neste trabalho. ${ }^{12}$

Já a taxa de câmbio real - índice de preços intersetorial (Ribeiro, 2006) é obtida efetuando-se a ponderação da taxa de câmbio real pela participação nas exportações brasileiras de cada país. No caso da Ásia, considera-se a média ponderada das taxas de câmbio do Real com a moeda dos principais parceiros, a saber: China, Japão, Coreia do Sul e Hong Kong. Para a taxa de câmbio real com a União Europeia, considera-se a relação do Real com o Euro. Para o NAFTA e o Mercosul são construídas pela média ponderada da taxa real da moeda brasileira com cada membro do seu bloco, a saber: Estados Unidos, Canadá e México; e Argentina, Paraguai e Uruguai, respectivamente.

Cabe ressaltar que as taxas de câmbio real aqui utilizadas são taxas multilaterais (chamaremos de taxa de câmbio real). As taxas de câmbio real são elaboradas pela Funcex e utilizam como deflator o Índice de Preços ao Consumidor/Disponibilidade Interna (IPC/DI)/Fundação Getulio Vargas (FGV). Por fim, constrói-se uma medida da volatilidade da taxa de câmbio, que possibilita captar movimentos gerais das flutuações na taxa de câmbio real, a qual é construída pela média móvel de desvios-padrão do logaritmo das séries da taxa de câmbio real.

Por fim, cabe salientar que estimações agregadas para cada fator também serão efetuadas, com o intuito de "comparar" os resultados com inferências presentes na literatura. Nesse caso, as variáveis índice de quantum e índice de preços das exportações serão obtidas de forma similar ao apresentado anteriormente. A variável de absorção externa consiste no valor das importações mundiais dos principais parceiros comerciais (conforme definido anteriormente), e a taxa de câmbio real é em relação à cesta de 13 moedas (deflator: IPC/FGV). ${ }^{13}$

12 A construção dessa variável dá-se pelas importações mundiais de cada país membro do parceiro comercial, ponderada pela participação de cada país nas exportações totais do Brasil. 13 As variáveis correspondentes às exportações, preços e demanda externa foram dessazonalizadas pelo "Método de Ajustamento Sazonal Mensal X-12". 


\subsection{Comportamento das variáveis}

A partir de meados dos anos 2000, o comportamento das exportações brasileiras apresentou consideráveis transformações, tanto no que diz respeito aos destinos quanto na classe de produtos comercializados. Portanto, para atender aos objetivos do estudo, inicialmente apresenta-se o comportamento das variáveis para o período de janeiro de 1999 a junho de 2013.

Na Figura 1, observamos o comportamento do índice de quantum total das exportações de produtos básicos e manufaturados, bem como os seus respectivos índices de preços, a demanda externa e o comportamento da taxa de câmbio. Com relação às séries, cabe destacar o comportamento ascendente do quantum exportado de produtos básicos, enquanto o quantum exportado de produtos manufaturados sofreu forte queda em meados de 2009. Com relação ao índice de demanda externa, percebe-se que esta é crescente até meados de 2009, quando tem sua trajetória interrompida, retornando a crescer na sequência.

Por fim, observa-se uma sintonia no comportamento dos índices de preços e da taxa de câmbio, verificando-se, principalmente, um comportamento de valorização cambial, com dois momentos de considerável desvalorização, entre 2001-2003 e 2008-2009.

Flgura 1 Índice de quantum e de preços (produtos básicos e manufaturados), da demanda externa e da taxa de câmbio real - valores em logaritmo (Base: Média $2000=100$ )

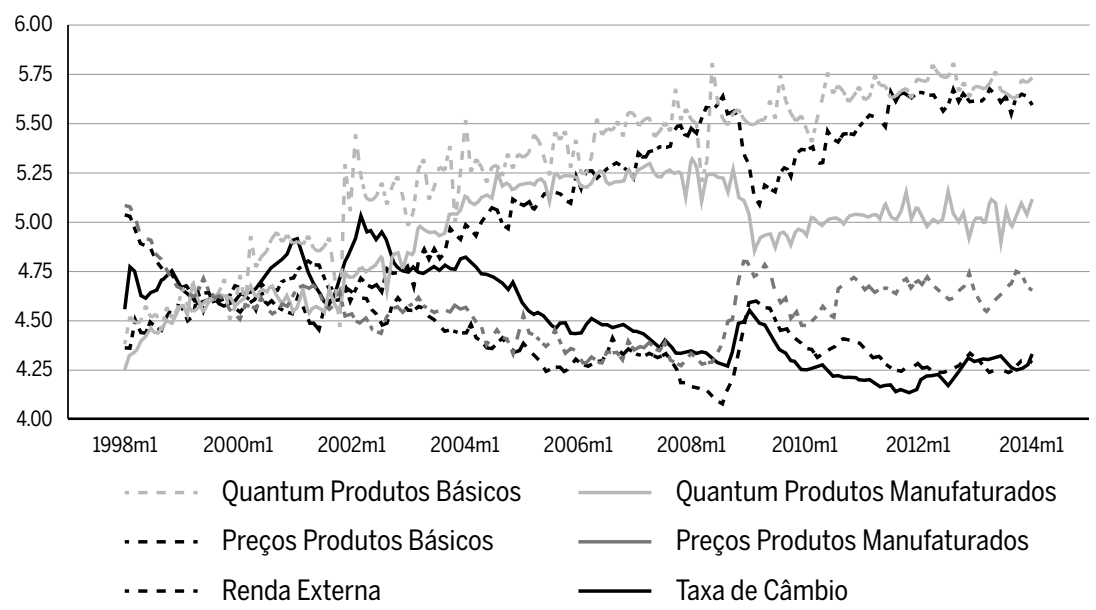

Fonte: Índice de quantum, preços e demanda externa das exportações brasileiras (Funcex). Taxa de câmbio real (IPC/FGV). 
Para demonstrar essa mudança do perfil da pauta de exportações mencionado anteriormente, na Figura 2, apresenta-se a distribuição geográfica das exportações brasileiras de produtos básicos e manufaturados, para a Ásia, o NAFTA, a União Europeia e o Mercosul. Em 2012, o Brasil exportou cerca de US\$243 bilhões em mercadorias. Desse total, 84\% corresponderam a produtos básicos e manufaturados ( $47 \%$ e $37 \%$, respectivamente). Tendo em vista a pauta desagregada de exportações, percebe-se a grande concentração de destinos, no caso dos produtos básicos (Ásia e União Europeia correspondendo a, aproximadamente, 75\% em 2013), e a considerável diversificação, no caso dos manufaturados (com destaque principal para o Mercosul, 27\% em 2013).

Historicamente, as exportações brasileiras têm se solidificado por uma característica de diversificação geográfica. Essa diversificação tem sido fundamental para a manutenção do desempenho das exportações na última década, não as deixando completamente dependentes dos parceiros comerciais tradicionais. No entanto, o cenário de alta dos preços das commodities e o crescimento da demanda mundial têm gerado mudanças no desempenho dos países de destino das exportações.

\section{Figura 2 Participação dos destinos selecionados nas exportações brasileiras, por fator}

\section{agregado}

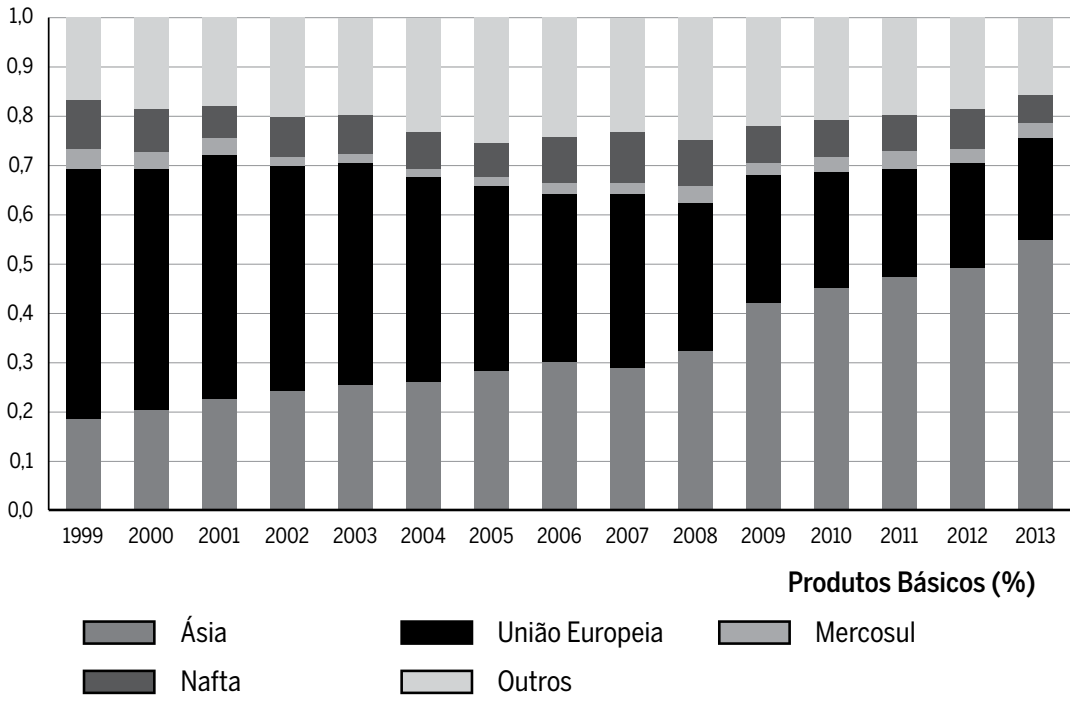

(continua) 
Figura 2 (continuação)

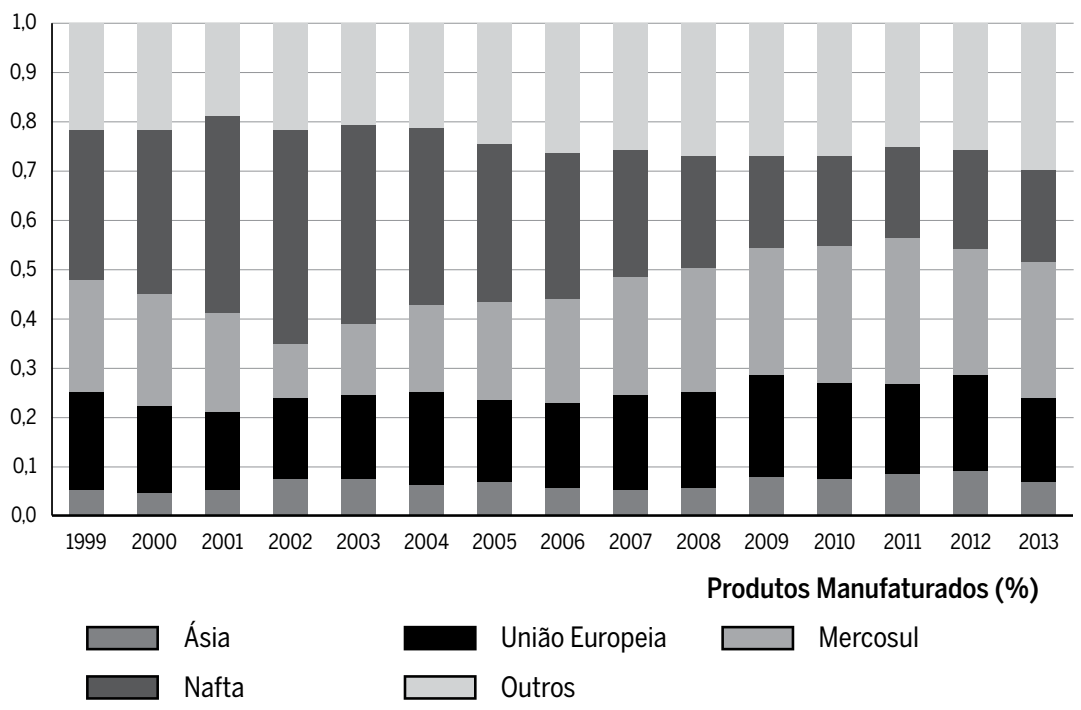

Fonte: MDIC/SECEX (sistema ALICEWEB) e FUNCEX.

\subsection{Metodologia}

A partir da relação apresentada na equação (1), serão estimados os parâmetros de interesse - elasticidades - que possibilitam melhor compreender os fatores que influenciam os fluxos comerciais setoriais. A fim de manter a elasticidade constante, as relações a serem estimadas são dadas pela seguinte equação ${ }^{14}$ :

$$
\begin{aligned}
& \operatorname{lnqx}_{i, j, t}=\alpha_{i, j, t-1}+\beta_{1 i j} \operatorname{lnpr}_{i, j, t-1}+\beta_{2 i j} \operatorname{lnrenda}_{j, t-1}+\beta_{3 i j} \ln t c_{j, t-1}+ \\
& +\beta_{4 i j} \ln v_{j, t-1}+\varepsilon_{i, j, t-1}
\end{aligned}
$$

em que $i \in$ (Básicos,Manufaturados) e $j \in($ Ásia,Nafta, União Europeia,Mercosul), e as variáveis são assim descritas:

- $\ln q x_{i, j, t}$ representa o logaritmo do índice de quantum das exportações brasileiras de produtos do fator agregado $i$ para o destino j; 
- $\operatorname{lnpr}_{i, j, t-1}$ representa o logaritmo do índice de preços relativos das exportações brasileiras de produtos do fator agregado $i$ para o destino $j$ no período $t-1$;

- Inrenda $a_{j, t-1}$ representa o logaritmo da proxy do índice de renda externa do destino $j$ no período $t-1$, conforme definida acima;

- $\operatorname{lntc}_{j, t-1}$ representa o logaritmo da taxa de câmbio real do Brasil com o parceiro comercial $j$ no período $t-1$;

- $\ln v_{j, t-1}$ representa o logaritmo da volatilidade cambial em relação a cada bloco de destino $j$ no período $t-1$;

- $\varepsilon_{i, j, t-1}$ representa o termo de erro aleatório.

Os parâmetros de interesse são representados pelos coeficientes $\beta_{1 i j}, \beta_{2 i j}$, $\beta_{3 i j}$ e $\beta_{4 i j}$.

Considerando a equação (4), nota-se que será estimado um total de oito equações, as quais, diferentemente de estudos anteriores, buscam a identificação desagregada das relações dadas pelos parâmetros $\beta$.

O tratamento mais adequado quando se trabalha com séries de tempo consiste na investigação sobre a estacionariedade e a presença ou não de cointegração entre as séries. Verificada a ordem de integração das variáveis, analisa-se a cointegração, que permite verificar se existe uma relação de longo prazo entre as variáveis. Constatada uma relação de longo prazo entre as séries, os modelos devem ser ajustados através do método de Vetores com Correção de Erros que, como o próprio nome expressa, tem como objetivo corrigir as relações de cointegração (Johnston; Dinardo, 2001).

Para avaliar a condição de estacionariedade das variáveis, aplicam-se os testes apresentados por Hamilton (1994), Greene (2008), Bueno (2008) e Enders (2010), a saber: o Teste Augmented Dickey-Fuller (ADF) (Dickey; Fuller, 1979), de PP (Phillips; Perron, 1988) e KPSS (Kwiatkowski et al. 1992).

O modelo de substitutos imperfeitos utilizado é especificado dentro de uma estrutura de correção de erros. Essa abordagem fornece informações sobre as relações de longo prazo, bem como da dinâmica de curto prazo. De maneira geral, Greene (2008), Bueno (2008) e Enders (2010) apresentam dois métodos de determinação das relações de cointegração: a abordagem de Engle e Granger (1987) e o Teste de Johansen [Johansen (1988) e Johansen e Joselius (1990)]. O teste de cointegração de Johansen (metodologia baseada em Vetores Autorregressivos (VAR), aqui explorado, está apoiado numa estrutura de máxima verossimilhança, enquanto a abordagem de 
Engle e Granger está baseada nos resíduos. Genericamente, as relações estimadas são dadas pela equação a seguir:

$$
\Delta X_{t}=\alpha\left[\beta^{\prime} X_{t-1}+\mu_{1}+\delta_{1} t\right]+\mu_{2}+\delta_{2}+\sum_{i=1}^{n} \gamma_{i} \Delta X_{t-1}+\varepsilon_{t}
$$

onde: $\Delta X_{t}$ é o vetor de variáveis sujeitas ao teste de cointegração; $\beta^{\prime}$ é a matriz que contém os vetores de cointegração (relações de longo prazo); $\alpha$ é a matriz de coeficientes de ajustamento que determina a velocidade em que os desequilíbrios de curto prazo são remetidos ao longo prazo; $\gamma_{i}$ representa os coeficientes de curto prazo; $\Delta$ é o operador de primeira diferença e $\varepsilon_{t}$ é um termo de resíduo aleatório. $O$ teste de cointegração de Johansen trabalha com as propriedades da matriz de coeficientes da relação de cointegração $\beta^{\prime}$ (a matriz de coeficientes das variáveis defasadas). Conforme Enders (2010), a característica-chave a ser observada na equação (5) é o rank da matriz $\beta$ ', que é igual ao número de vetores cointegrantes independentes.

Como proposto por Johansen $(1988 ; 1992)$, para testar a existência e o número de vetores cointegrados, são aplicadas as estatísticas de máximo autovalor $\left(\lambda_{\text {tracso }}\right)$ e a estatística traço $\left(\lambda_{\text {tragso }}\right)$, já que, na prática, podem ser obtidas apenas as estimativas de $\beta^{\prime}$ e suas raízes características. Conforme Enders (2010, p. 391), esses dois testes estatísticos testam o número de raízes características diferentes da unidade.

Devido aos resultados obtidos nos testes de raiz unitária e de cointegração, a relação econômica entre as variáveis apresentada na equação (4) foi estimada pela metodologia de autorregressão vetorial com mecanismos de correção de erros. Portanto, a especificação a ser estimada é obtida através da equação (5), em que $X_{t}$ contém todas as variáveis expressas na equação (4).

\section{Resultados e discussões}

Nesta seção são apresentados os resultados das elasticidades estimadas para a relação de longo prazo, traçando-se um cenário comparativo interclasses, de fator agregado, e inter-regional, além do comparativo com as inferências já presentes na literatura.

Através dos testes de estacionariedade de ADF, PP e KPSS, todas as variáveis podem ser consideradas como integradas de ordem um, isto é, 
$I(1) .{ }^{15}$ Verificada a ordem de integração das variáveis, parte-se para a análise da relação de cointegração. A Tabela 1, a seguir, reporta os testes de cointegração de Johansen para os oito casos analisados.

Tabela 1 Teste de cointegração - classe de produtos básicos(b) e manufaturados(M)

\begin{tabular}{|c|c|c|c|c|c|c|c|c|c|c|c|}
\hline $\mathbf{H}_{0}$ & $H_{1}$ & $\begin{array}{r}\text { Est. } \\
\lambda_{\text {traco }} \\
\text { (B) }\end{array}$ & $\begin{array}{l}\text { Est. } \\
\lambda_{\text {traco }} \\
\text { (M) }\end{array}$ & $\begin{array}{l}\text { v.c. } \\
5 \%\end{array}$ & $\begin{array}{l}\text { V.C. } \\
1 \%\end{array}$ & $H_{0}$ & $H_{1}$ & $\begin{array}{c}\text { Est. } \\
\lambda_{\text {traco }} \\
\text { (B) }\end{array}$ & $\begin{array}{l}\text { Est. } \\
\lambda_{\text {traco }} \\
\text { (M) }\end{array}$ & $\begin{array}{l}\text { v.c. } \\
5 \%\end{array}$ & $\begin{array}{l}\text { v.c. } \\
1 \%\end{array}$ \\
\hline \multicolumn{12}{|c|}{ Ásia* } \\
\hline$r=0$ & $r>0$ & 90.09 & 93.83 & 68.52 & 76.07 & $r=0$ & $r=1$ & 46.77 & 55.33 & 33.46 & 38.77 \\
\hline$r \leq 1$ & $r>1$ & 43.32 & 38.50 & 47.21 & 54.46 & $r=1$ & $r=2$ & 24.96 & 21.86 & 27.07 & 32.24 \\
\hline$r \leq 2$ & $r>2$ & 18.36 & 16.64 & 29.68 & 35.65 & $r=2$ & $r=3$ & 10.57 & 9.78 & 20.97 & 25.52 \\
\hline \multicolumn{12}{|c|}{ NAFTA* } \\
\hline$r=0$ & $r>0$ & 99.81 & 101.62 & 68.52 & 76.07 & $r=0$ & $r=1$ & 60.04 & 52.09 & 33.46 & 38.77 \\
\hline$r \leq 1$ & $r>1$ & 39.77 & 49.53 & 47.21 & 54.46 & $r=1$ & $r=2$ & 17.45 & 26.57 & 27.07 & 32.24 \\
\hline$r \leq 2$ & $r>2$ & 22.32 & 22.97 & 29.68 & 35.65 & $r=2$ & $r=3$ & 13.03 & 14.47 & 20.97 & 25.52 \\
\hline \multicolumn{12}{|c|}{ União Europeia* } \\
\hline$r=0$ & $r>0$ & 101.87 & 104.83 & 68.52 & 76.07 & $r=0$ & $r=1$ & 70.19 & 61.59 & 33.46 & 38.77 \\
\hline$r \leq 1$ & $r>1$ & 31.67 & 43.24 & 47.21 & 54.46 & $r=1$ & $r=2$ & 14.75 & 25.04 & 27.07 & 32.24 \\
\hline$r \leq 2$ & $r>2$ & 16.91 & 18.21 & 29.68 & 35.65 & $r=2$ & $r=3$ & 8.00 & 9.48 & 20.97 & 25.52 \\
\hline \multicolumn{12}{|c|}{ Mercosul* } \\
\hline$r=0$ & $r>0$ & 95.65 & 79.61 & 59.46 & 66.52 & $r=0$ & $r=1$ & 59.83 & 36.15 & 30.04 & 35.17 \\
\hline$r \leq 1$ & $r>1$ & 35.82 & 43.46 & 39.89 & 45.58 & $r=1$ & $r=2$ & 17.94 & 27.24 & 23.80 & 28.82 \\
\hline$r \leq 2$ & $r>2$ & 17.87 & 16.22 & 24.31 & 29.75 & $r=2$ & $r=3$ & 11.42 & 11.04 & 17.89 & 22.99 \\
\hline
\end{tabular}

* Com termo de tendência linear (constante). $H_{0}=$ Hipótese Nula; $H_{1}=$ Hipótese Alternativa.

$\mathrm{Na}$ Tabela 1, estão reportadas as estatísticas $\lambda_{\text {traco }}$ e $\lambda_{\text {máx }}$ para a classe de produtos básicos e manufaturados com destino à Ásia, NAFTA, União Europeia e Mercosul, respectivamente. A estatística $\lambda_{\text {máx }}$ testa a existência de $r$ vetores de cointegração contra a hipótese alternativa de $r+1$ vetores, enquanto a estatística $\lambda_{\text {traço }}$ testa a existência de mais que $r$ vetores de cointegração contra a hipótese alternativa de, no mínimo, $r+1$ vetores.

Os resultados, tanto da estatística do teste traço quanto da estatística do máximo autovalor para as quatro equações especificadas, sugerem a rejeição da hipótese de não cointegração, ou seja, $(r=0)$, no nível de signi15 Os resultados são suprimidos por restrição de espaço e podem ser obtidos mediante solicitação aos autores. 
ficância de 5\%. Não se rejeita a hipótese nula da existência de um vetor de cointegração, no nível de significância de $5 \%$. Conclui-se que existe uma relação de cointegração entre a demanda por produtos básicos da Ásia, do NAFTA, da União Europeia e do Mercosul e seus determinantes; embora as variáveis na equação sejam não estacionárias (em nível), sua combinação linear é estacionária.

Por fim, corroborando as conclusões frente às demais classes de produtos, com as exportações de manufaturados, não é diferente. Verifica-se a ocorrência de, ao menos, um vetor de cointegração entre as séries, no nível de $5 \%$, apontando uma relação de longo prazo entre elas. Portanto, a presença do vetor de cointegração indica que qualquer desvio da relação entre a demanda por exportações de manufaturados - e dos demais setores - e seus determinantes é temporário.

Os resultados apresentados na Tabela 1 indicam a presença de uma relação de equilíbrio de longo prazo entre a demanda por exportações setoriais com destino à Ásia, ao NAFTA, à União Europeia e ao Mercosul e seus determinantes. Para examinar os aspectos relacionados à natureza das relações de longo prazo nos dados, parte-se para a normalização da relação de cointegração para o primeiro vetor, ou seja, o quantum das exportações setoriais. Dessa forma, os resultados para ambos os testes de cointegração sugerem que existe uma relação de equilíbrio de longo prazo real entre exportações, renda, preço e taxa de câmbio, para todos os destinos estudados.

\subsection{Elasticidades das exportações de produtos básicos}

Os resultados expressos nas tabelas 2 a 5 apresentam os coeficientes das equações de cointegração, a qual é expressa com variáveis explicativas defasadas num período. As elasticidades de longo prazo da demanda por exportações de produtos básicos encontram-se na Tabela 2, a seguir.

As colunas ímpares apresentam as estimativas incluindo o termo de volatilidade cambial, no entanto, como em muitas das estimativas, seu coeficiente mostrou-se não significativo. Nas colunas pares (2, 4, 6 e 8), estão as estimativas sem o termo de volatilidade cambial, as quais serão nossas estimativas preferidas.

As elasticidades da demanda por exportações de produtos básicos mostram que, entre os quatro destinos selecionados, o quantum exportado é 
mais sensível aos movimentos da variável de absorção externa, com o coeficiente variando de 1,77 (Ásia) a 0,14 (Mercosul).

Cabe notar que os dois principais destinos de produtos básicos brasileiros (Ásia e União Europeia representaram 76\% das exportações de produtos básicos em 2013) também apresentam coeficientes altamente significativos para as variáveis de preços relativos e da taxa de câmbio.

Tabela 2 Elasticidades das exportações brasileiras de produtos básicos

\begin{tabular}{|c|c|c|c|c|c|c|c|c|}
\hline \multirow{2}{*}{$\begin{array}{l}\text { Elastici- } \\
\text { dades } \\
\text { Longo } \\
\text { Prazo }\end{array}$} & \multicolumn{2}{|r|}{ Ásia } & \multicolumn{2}{|c|}{ União Europeia } & \multicolumn{2}{|r|}{ NAFTA } & \multicolumn{2}{|r|}{ Mercosul } \\
\hline & (1) & (2) & (3) & (4) & (5) & (6) & (7) & (8) \\
\hline $\begin{array}{l}\text { Preços } \\
\text { relativos }\end{array}$ & $\begin{array}{r}* * *-0,8569 \\
(0,1441)\end{array}$ & $\begin{array}{r}* * *-0,8238 \\
(0,1528)\end{array}$ & $\begin{array}{r}* * *-0,3561 \\
(0,0506)\end{array}$ & $\begin{array}{r}* * *-0,3575 \\
(0,0506)\end{array}$ & $\begin{array}{l}-0,0616 \\
(0,1490)\end{array}$ & $\begin{array}{r}0,0235 \\
(0,1499)\end{array}$ & $\begin{array}{r}0,0001 \\
(0,0659)\end{array}$ & $\begin{array}{r}0,0907 \\
(0,0652)\end{array}$ \\
\hline $\begin{array}{l}\text { Renda } \\
\text { externa }\end{array}$ & $\begin{array}{r}* * 1,8092 \\
(0,0989)\end{array}$ & $\begin{array}{r}* * * 1,7672 \\
(0,0965)\end{array}$ & $\begin{array}{r}* * 0,8029 \\
(0,0690)\end{array}$ & $\begin{array}{r}* * * 0,8403 \\
(0,0541)\end{array}$ & $\begin{array}{r}* * 2,1733 \\
(0,2420)\end{array}$ & $\begin{array}{r}* * * 1,6643 \\
(0,1989)\end{array}$ & $\begin{array}{r}* * * 0,2114 \\
(0,0508)\end{array}$ & $\begin{array}{r}* * * 0,1432 \\
(0,0458)\end{array}$ \\
\hline $\begin{array}{l}\text { Taxa de } \\
\text { câmbio }\end{array}$ & $\begin{array}{r}* * * 0,5068 \\
(0,1891)\end{array}$ & $\begin{array}{r}* * * 0,4545 \\
(0,1968)\end{array}$ & $\begin{array}{r}* * * 0,5135 \\
(0,0624)\end{array}$ & $\begin{array}{r}* * * 0,5108 \\
(0,0615)\end{array}$ & $\begin{array}{r}0,2472 \\
(0,2264)\end{array}$ & $\begin{array}{r}0,2805 \\
(0,2281)\end{array}$ & $\begin{array}{r}0,0744 \\
(0,0508)\end{array}$ & $\begin{array}{l}-0,0026 \\
(0,0530)\end{array}$ \\
\hline $\begin{array}{l}\text { Volati- } \\
\text { lidade } \\
\text { cambial }\end{array}$ & $\begin{array}{r}- \\
0,0733 \\
(0,0703)\end{array}$ & $\begin{array}{l}- \\
- \\
-\end{array}$ & $\begin{array}{r}- \\
0,0306 \\
(0,0328)\end{array}$ & $\begin{array}{l}- \\
- \\
-\end{array}$ & $\begin{array}{r}- \\
* * * 0,2167 \\
(0,0821)\end{array}$ & $\begin{array}{l}- \\
- \\
-\end{array}$ & $\begin{array}{r}- \\
{ }^{* *} 0,0637 \\
(0,0289)\end{array}$ & $\begin{array}{l}- \\
- \\
-\end{array}$ \\
\hline$E C T_{-1}$ & $\begin{array}{r}-0,4261 \\
(0,0996)\end{array}$ & $\begin{array}{r}-0,4155 \\
(0,0924)\end{array}$ & $\begin{array}{r}-0,8910 \\
(0,108)\end{array}$ & $\begin{array}{l}-0,8631 \\
(0,1009)\end{array}$ & $\begin{array}{r}-0,4897 \\
(0,0883)\end{array}$ & $\begin{array}{l}-0,5056 \\
(0,0874)\end{array}$ & $\begin{array}{r}-0,9457 \\
(0,0994)\end{array}$ & $\begin{array}{l}-0,8938 \\
(0,1044)\end{array}$ \\
\hline
\end{tabular}

Erros-padrão estimados entre parênteses. ECT : Termo de correção de erros. Significância dos parâmetros: ${ }^{* *} p<0,01,{ }^{* *} p<0,05,{ }^{*} p<0,1$.

Especificamente para a Ásia, suspeita-se que um dos motivos da elevação da participação asiática nas compras de produtos dessa classe seja o crescimento da sua demanda interna, refletida na alta elasticidade-renda $(1,77)$. Portanto, dado o comportamento elástico do quantum exportado frente aos movimentos do nível de renda asiático, uma elevação de 10,0\% no poder aquisitivo provoca elevação de $17,7 \%$ no quantum exportado, enquanto essa mesma elevação nos índices de preços relativos e da taxa de câmbio acarretam, respectivamente, um decréscimo de $8,2 \%$ e uma elevação de $4,5 \%$ no quantum exportado. A magnitude superior das elasticidades de preços relativos $(-0,82)$ em relação às da taxa de câmbio $(0,45)$, em módulo, indica que os efeitos de uma depreciação cambial seriam parcialmente anulados pelos efeitos negativos do índice de preços. 
No que se refere ao quantum exportado para a União Europeia, do mesmo modo que nas exportações para a Ásia, verifica-se a relação principal do comportamento das exportações com o nível de renda, no qual uma variação de 10,0\% acarreta variação de 8,4\% no quantum exportado.

Quanto ao impacto dos índices de preços intra e intersetoriais, observa-se que o efeito é inelástico, $-0,36$ para os preços relativos e 0,51 para a taxa de câmbio. Quando se compara a sensibilidade das exportações aos movimentos da taxa de câmbio para a União Europeia com relação aos demais destinos em análise, verifica-se maior variação para esse destino.

$\mathrm{Na}$ análise das elasticidades das exportações para o NAFTA e o Mercosul, diferentemente das relações encontradas para a Ásia e a União Europeia, os coeficientes relacionados ao índice de preços relativos e da taxa de câmbio, em ambas as estimações, mostraram-se não significativos.

Dessa forma, o quantum exportado para o NAFTA e o Mercosul é impactado, predominantemente, pela renda dos parceiros, com coeficientes de 1,66 e 0,14, respectivamente. $O$ baixo determinismo do nível de renda sobre a demanda por exportações do Mercosul (elasticidade de 0,14 ) pode estar associado à perda do poder de compra e, consequentemente, à redução do consumo da economia argentina (principal parceiro neste bloco) no início da última década.

Tabela 3 Elasticidade da demanda de exportações de produtos básicos: comparativo com resultados anteriores

\begin{tabular}{lrrr|r|r}
\hline $\begin{array}{l}\text { Autores/ } \\
\text { Elasticidades }\end{array}$ & $\begin{array}{r}\text { Preços } \\
\text { relativos }\end{array}$ & $\begin{array}{r}\text { Renda } \\
\text { externa }\end{array}$ & $\begin{array}{r}\text { Taxa de } \\
\text { câmbio }\end{array}$ & $\begin{array}{r}\text { Volatilidade } \\
\text { cambial }\end{array}$ \\
\hline Castro e Cavalcanti (1997) & - & 0,27 & 0,91 & - \\
\hline Paiva (2003) & - & 1,80 & 0,64 & $-0,16$ \\
\hline Ribeiro (2006) & - & 1,70 & 0,53 & 0,04 \\
\hline Meyer (2008) & $-0,57$ & 0,77 & - & - \\
\hline & $* * *-0,4816$ & ${ }^{* * *} 1,1932$ & $* * * 0,3152$ & 0,0345 \\
Estudo atual & $(0,1251)$ & $(0,0932)$ & $(0,0958)$ & $(0,0736)$ \\
\cline { 2 - 5 } & $* * *-0,4414$ & $* * * 1,1370$ & $* * * 0,3153$ & - \\
& $(0,1190)$ & $(0,0554)$ & $(0,0933)$ & - \\
\hline
\end{tabular}

Significância dos parâmetros: ${ }^{* *} p<0,01,{ }^{* *} p<0,05,{ }^{*} p<0,1$.

Comparando os resultados obtidos com os presentes na literatura (Tabela 3), dada a inexistência de estudos avaliando as elasticidades para os des- 
tinos selecionados (e desagregadas da forma aqui desenvolvida), foi estimada uma nova equação, que engloba as exportações totais de produtos básicos Essa comparação está restrita às variáveis comuns às formulações e dar-se-á somente no âmbito das elasticidades de longo prazo.

Conforme as elasticidades de estudos apresentados na Tabela 3, pode-se dizer que, independentemente dos métodos utilizados, existe certa convergência dos resultados, principalmente no que se refere às elasticidades preço, renda e taxa de câmbio. Perante a elasticidade-preço da demanda, verifica-se que o resultado aqui encontrado para as exportações de produtos básicos situa-se muito próximo ao encontrado por Meyer (2008). Constata-se, ainda, que a elasticidade da taxa de câmbio também é inferior aos resultados encontrados por Paiva (2003) e Ribeiro (2006).

A estimativa para a elasticidade-renda da demanda de produtos básicos é ligeiramente inferior às encontradas nos estudos de Paiva (2003) e Ribeiro (2006) e superior aos estudos de Castro e Cavalcanti (1997) e Meyer (2008). No entanto, cabe ressaltar que os resultados aqui encontrados seguem as inferências da literatura no que diz respeito ao impacto mais acentuado da variável renda externa sobre o comportamento das exportações. Com relação ao impacto da volatilidade cambial frente aos resultados da literatura brasileira, não se pode tirar quaisquer conclusões definitivas acerca de seu impacto, embora essa não seja nossa especificação preferida. ${ }^{16}$

\subsection{Elasticidades das exportações de produtos manufaturados}

Os resultados obtidos para os produtos manufaturados são apresentados na Tabela 4, a seguir. Da mesma forma que na seção anterior, foram estimadas as especificações com e sem a volatilidade cambial, embora o foco esteja nos coeficientes sem a inclusão da volatilidade cambial (colunas pares). De maneira semelhante às exportações de produtos básicos, na qual a renda era o principal determinante das exportações, o quantum exportado de manufaturados para o Mercosul, a União Europeia e o NAFTA é mais sensível ao comportamento do nível de renda. Apenas no caso das exportações para a Ásia, que representa a menor participação nas exportações de manufatu-

16 Em estudos para outros países, também, se verifica esse efeito dúbio da volatilidade sobre o quantum exportado, porém, Arize (1995), Sauer e Bonara (2001) e Cheung e Sengupta (2013) encontram impacto negativo. 
rados do Brasil (média de 6,4\% no período analisado), o principal determinante das exportações fora o índice de preços, com coeficiente de $-2,92$. No entanto, os coeficientes associados ao nível de renda e à taxa de câmbio também se apresentaram acima da unidade, 2,21 e 1,61, respectivamente.

$\mathrm{Na}$ sequência, analisam-se as relações estimadas para os principais destinos das exportações de produtos manufaturados do Brasil. De 1999 a 2013, a participação média do NAFTA, Mercosul e União Europeia foi, respectivamente, $28,7 \%, 22,4 \%$ e $18,3 \%$. Iniciando com o Mercosul, verifica-se que as exportações são mais sensíveis à renda externa, com coeficiente superior a 1,70. Embora inferior, a elasticidade preços relativos da demanda é superior à unidade em termos absolutos $(-1,14)$. Por outro lado, o comportamento da demanda do Mercosul frente a movimentos da taxa de câmbio é inelástico, da ordem de 0,46 .

$\mathrm{Na}$ análise das elasticidades das exportações para o NAFTA, verifica-se a elevada dependência do quantum exportado em relação ao nível de renda. Dessa forma, tendo em vista o coeficiente aqui encontrado, pode-se apontar que uma variação de 10,0\% no nível de renda acarreta uma variação de $22,9 \%$ no quantum exportado. Com menor intensidade, mas ainda altamente elástica, verifica-se a relação negativa, como proposto teoricamente, do índice de preços relativos, $-2,08$. Destaca-se, ainda o padrão inelástico da elasticidade da demanda de manufaturados frente aos movimentos da taxa de câmbio, coeficiente de 0,84.

Por fim, apesar da instabilidade financeira vivida pela União Europeia nos últimos anos, no longo prazo, a variável renda continua sendo o principal determinante das exportações brasileiras de manufaturados, embora com impacto relativamente inferior ao encontrado para os demais parceiros comerciais. Os resultados apontam que uma variação de $10 \%$ no nível de renda estimula uma variação de $11,1 \%$ na demanda por exportações.

Quanto às elasticidades preço e taxa de câmbio, a magnitude dos coeficientes estimados são significativamente inferiores aos estimados para os demais destinos. Portanto, variações de 10,0\% no nível de preço e na taxa de câmbio, dados os valores das elasticidades, provocam variações de $-5,2 \%$ e $3,9 \%$ no quantum exportado, respectivamente.

Realizando agora uma análise comparativa com as demais estimativas de elasticidades presentes na literatura, pode-se inferir sobre a trajetória dos resultados aqui encontrados, vide as tabelas 3 e 5 . Ao analisar as tabelas 3 e 5 , pode-se dizer que, dado o número de estudos realizados, os 
pesquisadores dessa área têm voltado suas atenções mais para o setor de manufaturados do que para os produtos básicos.

Tabela 4 Elasticidades das exportações brasileiras de produtos manufaturados

\begin{tabular}{|c|c|c|c|c|c|c|c|c|}
\hline \multirow{2}{*}{$\begin{array}{l}\text { Elastici- } \\
\text { dades } \\
\text { Longo } \\
\text { Prazo }\end{array}$} & \multicolumn{2}{|r|}{ Ásia } & \multicolumn{2}{|c|}{ União Europeia } & \multicolumn{2}{|r|}{ NAFTA } & \multicolumn{2}{|r|}{ Mercosul } \\
\hline & (1) & (2) & (3) & (4) & (5) & (6) & (7) & (8) \\
\hline $\begin{array}{l}\text { Preços } \\
\text { relativos }\end{array}$ & $\begin{array}{r}* * * 2,7976 \\
(0,3401)\end{array}$ & $\begin{array}{r}* * * 2,9160 \\
(0,3509)\end{array}$ & $\begin{array}{r}* * * 0,5709 \\
(0,0939)\end{array}$ & $\begin{array}{r}* * * 0,5219 \\
(0,0903)\end{array}$ & $\begin{array}{r}* * *-2,0174 \\
(0,1193)\end{array}$ & $\begin{array}{r}* * *-2,0827 \\
(0,1321)\end{array}$ & $\begin{array}{r}* * * 2,2991 \\
(0,5543)\end{array}$ & $\begin{array}{r}* * *-1,1350 \\
(0,3568)\end{array}$ \\
\hline $\begin{array}{l}\text { Renda } \\
\text { externa }\end{array}$ & $\begin{array}{r}* * * 1,9214 \\
(0,2232)\end{array}$ & $\begin{array}{r}* * * 2,2170 \\
(0,2292)\end{array}$ & $\begin{array}{r}* * * 1,2063 \\
(0,1207)\end{array}$ & $\begin{array}{r}* * * 1,1105 \\
(0,0862)\end{array}$ & $\begin{array}{r}* * * 2,1403 \\
(0,1187)\end{array}$ & $\begin{array}{r}* * * 2,2906 \\
(0,1216)\end{array}$ & $\begin{array}{r}* * * 2,4166 \\
(0,4456)\end{array}$ & $\begin{array}{r}* * * 1,7058 \\
(0,2724)\end{array}$ \\
\hline $\begin{array}{l}\text { Taxa de } \\
\text { câmbio }\end{array}$ & $\begin{array}{r}* * * 1,5517 \\
(0,1312)\end{array}$ & $\begin{array}{r}* * * 1,6106 \\
(0,1360)\end{array}$ & $\begin{array}{r}* * * 0,3599 \\
(0,0423)\end{array}$ & $\begin{array}{r}* * * 0,3867 \\
(0,0363)\end{array}$ & $\begin{array}{r}* * * 0,8588 \\
(0,0275)\end{array}$ & $\begin{array}{r}* * * 0,8385 \\
(0,0292)\end{array}$ & $\begin{array}{r}* * * 0,6846 \\
(0,2275)\end{array}$ & $\begin{array}{r}* * * 0,4622 \\
(0,1508)\end{array}$ \\
\hline $\begin{array}{l}\text { Volati- } \\
\text { lidade } \\
\text { cambial }\end{array}$ & $\begin{array}{r}- \\
* * *-0,3808 \\
(0,1367)\end{array}$ & $\begin{array}{l}- \\
- \\
-\end{array}$ & $\begin{array}{r}- \\
0,0414 \\
(0,0628)\end{array}$ & $\begin{array}{l}- \\
- \\
-\end{array}$ & $\begin{array}{r}- \\
* * * 0,0943 \\
(0,0330)\end{array}$ & $\begin{array}{l}- \\
- \\
-\end{array}$ & $\begin{array}{r}- \\
-0,3439 \\
(0,2146)\end{array}$ & $\begin{array}{l}- \\
- \\
-\end{array}$ \\
\hline$E C T_{-1}$ & $\begin{array}{r}0,0306 \\
(0,0462)\end{array}$ & $\begin{array}{r}0,0416 \\
(0,0461)\end{array}$ & $\begin{array}{l}-0,3308 \\
(0,0908)\end{array}$ & $\begin{array}{l}-0,3690 \\
(0,0937)\end{array}$ & $\begin{array}{l}-0,0827 \\
(0,0870)\end{array}$ & $\begin{array}{l}-0,0936 \\
(0,0826)\end{array}$ & $\begin{array}{r}0,0420 \\
(0,0121)\end{array}$ & $\begin{array}{r}0,0484 \\
(0,0158)\end{array}$ \\
\hline
\end{tabular}

Obs.: Erros-padrão estimados entre parênteses. ECT ${ }_{-1}$ : Termo de correção de erros. Significância dos parâmetros: ${ }^{* * *} p<0,01,{ }^{* *} p<0,05,{ }^{*} p<0,1$.

A elasticidade-preço da demanda de exportações para os dois grupos de produtos encontrada neste trabalho situa-se relativamente próxima daquela encontrada por Meyer (2008). Do ponto de vista da elasticidade-renda, todos os estudos elencados apresentam o coeficiente com o sinal esperado (positivo), no entanto, entre os estudos realizados para o grupo de produtos manufaturados, este estudo apresenta estimativas muito próximas às de Paiva (2003), Ribeiro (2006) e Meyer (2008), com valores de 1,40, 1,32 e 1,33 , respectivamente.

Contudo, conforme mostrado na Tabela 5, a maioria das elasticidades-renda estimadas para os manufaturados - resultados obtidos por: Castro e Cavalcanti (1997), Paiva (2003), Ribeiro (2006), Meyer (2008) e Bonelli (2006) - encontram-se superiores à unidade. Diferentemente, no que se refere à elasticidade da demanda de exportações face à taxa de câmbio, aquela aqui encontrada é superior à maioria dos estudos apresentados na Tabela 5. Todas as demais elasticidades da taxa de câmbio apresentadas na Tabela 5 são inelásticas. Finalmente, quanto à elasticidade do quantum 
exportado de manufaturados em relação à volatilidade cambial, diferentemente dos resultados de Paiva (2003), Aguirre, Ferreira e Notini (2003), neste trabalho, a relação estimada é positiva e não significativa, ou seja, aproxima-se do resultado estimado por Ribeiro (2006), que a considera como nula.

Tabela 5 Elasticidade da demanda de exportações de produtos manufaturados: comparativo com resultados anteriores

\begin{tabular}{lrr|r|r}
\hline $\begin{array}{l}\text { Autores/ } \\
\text { Elasticidades }\end{array}$ & $\begin{array}{r}\text { Preços } \\
\text { relativos }\end{array}$ & $\begin{array}{r}\text { Renda } \\
\text { externa }\end{array}$ & $\begin{array}{r}\text { Taxa de } \\
\text { câmbio }\end{array}$ & $\begin{array}{r}\text { Volatilidade } \\
\text { cambial }\end{array}$ \\
\hline Amazonas e Barros (1995) & - & 1,07 & - & - \\
\hline Castro e Cavalcanti (1997) & - & 2,00 & 1,73 & - \\
\hline Pourchet (2003) & - & 0,70 & 0,50 & - \\
\hline Paiva (2003) & - & 1,40 & 0,44 & $-0,26$ \\
\hline Aguirre, Ferreira e Notini (2003) & - & 0,57 & 0,45 & $-0,77$ \\
\hline Ribeiro (2006) & - & 1,32 & $-0,02$ & 0.00 \\
\hline Meyer (2008) & $-0,91$ & 1,33 & - & \\
\hline Kawamoto, Santana e Fonseca (2013) & $-0,20$ & 0,77 & $-0,14$ & - \\
\hline Bonelli (2006) & $-0,49$ & 2,09 & - & - \\
\hline & $* * *-1,3351$ & $* * * 1,4434$ & $* * * 0,9016$ & 0,0749 \\
Estudo atual & $(0,2394)$ & $(0,1614)$ & $(0,1063)$ & $(0,0694)$ \\
\cline { 2 - 6 } & $* * *-1,1881$ & $* * * 1,2816$ & $* * * 0,8775$ & - \\
\hline
\end{tabular}

Significância dos parâmetros: ${ }^{* * *} p<0,01,{ }^{* *} p<0,05,{ }^{*} p<0,1$.

Embora na literatura brasileira não exista consenso sobre os valores encontrados para as elasticidades da demanda de exportações, no geral, as evidências empíricas parecem mostrar elevadas elasticidades-renda da demanda de exportações, sendo maiores que as elasticidades-preço. ${ }^{17}$ Também, as elasticidades renda e preço diferem significativamente segundo os grupos de produtos considerados. Por outro lado, os resultados anteriores parecem mostrar baixa elasticidade da taxa de câmbio sobre as exportações, chegando a ser negativa em alguns casos.

17 Para Oreiro, Lemos e Da Silva (2007), o crescimento das exportações de um país ou região, no longo prazo, é determinado pelo produto entre a elasticidade-renda das exportações e a taxa de crescimento da renda do resto do mundo. Ainda, capta a influência de fatores, como: conteúdo tecnológico, grau de diferenciação dos produtos e o valor adicionado a esses produtos. 
Ainda assim, neste trabalho, obteve-se uma estimativa elevada da elasticidade-câmbio, principalmente no que se refere aos produtos manufaturados. Com efeito, o quantum exportado de manufaturados mostrou-se com uma variação de aproximadamente 0,90 diante do câmbio, enquanto na classe de básicos o comportamento parece ser consideravelmente menos sensível ao câmbio, levando a inferir que os demandantes dessa classe de produtos são pouco sensíveis às variações cambiais.

Em relação à elasticidade-preço de ambas as classes de produtos, apresenta-se um resultado interessante. Através dos resultados das tabelas 3 e 5, verifica-se que a elasticidade-preço das exportações de produtos manufaturados é superior à de produtos básicos. Nesse aspecto, ressalta-se a importância da utilização do índice de preços relativos das exportações nas estimativas. Acredita-se que a maior elasticidade com relação ao nível de preços, verificada para a pauta de produtos manufaturados, provém do grau de substituição entre o bem exportado pelo Brasil e o exportado por uma economia concorrente.

À luz da Teoria das Vantagens Comparativas, como o Brasil apresenta vantagens na produção de bens com menor fator agregado (nesse caso, produtos básicos), é factível argumentar que se torna menos atraente para o país importador substituir as compras de bens básicos do Brasil pelo de outra economia. Pelo lado dos bens manufaturados, como existem diversas economias emergentes que apresentam uma estrutura industrial semelhante à da economia brasileira, é possível que bens semelhantes sejam encontrados no mercado internacional com maior facilidade. Portanto, por essa ótica, o maior grau de substituição dos produtos manufaturados torna esses bens mais sensíveis às variações dos preços.

Além disso, cabe destacar que o comportamento das exportações para os destinos selecionados segue um determinado padrão. Embora as magnitudes estimadas para os coeficientes difiram de destino para destino, é predominante o maior impacto desempenhado pela capacidade de absorção dos mercados de destino. Desse modo, pelos resultados aqui obtidos, parece recomendável uma estratégia de inserção no mercado externo que continue a dar atenção aos tradicionais mercados internacionais, bem como, no aprimoramento das relações comerciais com países que apresentam a sua demanda interna aquecida. ${ }^{18}$

18 As funções impulso-resposta para cada um dos destinos analisados, suprimidas por restrições de espaço, apresentam os resultados tradicionalmente encontrados na literatura. 


\section{Conclusões}

A contribuição deste estudo dá-se na caracterização do comércio do Brasil com seus principais parceiros comerciais - Ásia, NAFTA, União Europeia e Mercosul - através de uma análise desagregada por fator agregado (produtos básicos e manufaturados). A análise da demanda por exportações desagregadas, tanto por destinos geográficos quanto por classes de produtos, permite verificar certas particularidades da demanda local, em particular, no impacto desempenhado pela capacidade de absorção dos mercados de destino.

Em referência ao objetivo proposto, a equação de demanda, estimada através da modelagem de correção de erros, apresentou resultados satisfatórios, em especial as estimativas das elasticidades de longo prazo, em oposição aos comportamentos perceptíveis de instabilidade nas relações contemporâneas apresentadas pelas funções impulso-resposta. As elasticidades encontradas sugerem que a parcela de $74,0 \%$ das exportações para a Ásia - que consiste em bens básicos - é mais elástica à renda do que aos demais determinantes, enquanto as exportações de manufaturados respondem mais sensivelmente às variações dos preços.

Das exportações totais para o NAFTA, os $27,0 \%$ de produtos básicos são, comparativamente, mais sensíveis à elasticidade-renda, da mesma forma que os $54,0 \%$ de manufaturas. Com um padrão similar, no entanto com magnitudes ligeiramente inferiores, o quantum demandado de produtos básicos e manufaturados pela União Europeia e o Mercosul também são mais sensíveis ao comportamento da sua capacidade de importação.

As diferenças de magnitudes verificadas entre as elasticidades, tendo em vista os diferentes destinos das exportações, podem ser coerentes com a existência de diferenças no padrão de comércio entre o Brasil e as diferentes áreas de comércio. As exportações brasileiras para a Ásia e a União Europeia são fortemente orientadas na direção dos produtos básicos, enquanto as exportações para o NAFTA e o Mercosul são voltadas para os produtos manufaturados.

Frente às elasticidades (totais) para cada classe de produto agregado, pode-se inferir que a renda externa é o determinante principal, tanto na classe de produtos em que o Brasil, reconhecidamente, apresenta vantagens no comércio internacional (coeficiente de 1,14 para os produtos básicos), quanto na classe de produtos manufaturados (coeficiente de 1,28). 
Em relação à elasticidade-preço da demanda, pode-se inferir que é mais elevada para a classe de produtos manufaturados do que para os produtos básicos, o que acaba por implicar que a demanda por exportações de manufaturados é mais sensível a variações de preços do que a demanda por produtos básicos. Os coeficientes estimados da relação da taxa de câmbio com as exportações implicam que a estratégia de desvalorização, como forma de promover as exportações, é efetiva em ambas as situações. Assim, nesses casos, a depreciação da moeda nacional pode significar um estímulo às exportações.

\section{Referências}

AGUIRRE, A.; FERREIRA, A.; NOTINI, H. The Impact of Exchange Rate Volatility on Brazilian Manufactured Exports. Económica, v. 53, n. 1-2, p. 3-19, 2003.

ARIZE, A. C. The Effects of Exchange-Rate Volatility on Us Exports: an Empirical Investigation. Southern Economic Journal, v. 62, n. 1, p. 34-43, 1995.

ARIZE, A. C. Conditional Exchange-Rate Volatility and the Volume of Foreign Trade: Evidence from Seven Industrialized Countries. Southern Economic Journal, v. 64, n. 1, p. 235-254, 1997.

ASSEERY, A.; PEEL, D. A. The Effects of Exchange Rate Volatility on Exports: Some New Estimates. Economics Letters, v. 37, n. 2, p. 173-177, 1991.

BARROS, G. S. C.; BACCHI, M. R. P.; BURNQUIST, H. L. Estimação de equações de oferta de exportação de produtos agropecuários para o Brasil (1992/2000). Rio de Janeiro: IPEA, 2002. (Texto para discussão, n. 865.)

BONELLI, R. O desempenho exportador das firmas industriais brasileiras e o contexto macroeconômico. In: DE NEGRI, J. A.; ARAÚJO, B. C. P. O. DE, (Org.). As empresas brasileiras e o comércio internacional. Brasília: IPEA, 2006.

BRAGA, H. C.; MARKWALD, R. A. Funções de oferta e de demanda das exportações de manufaturados no Brasil: estimação de um modelo simultâneo. Revista Pesquisa e Planejamento Econômico, v. 13, n. 3, p. 707-744, 1983.

BUENO, R. S. Econometria de séries temporais. 2. ed. São Paulo: Cengage Learning, 2008.

CARDOSO, E.; DORNBUSCH, R. Uma equação para as exportações brasileiras de produtos manufaturados. Revista Brasileira de Economia, v. 34. n. 3, p. 429-438. 1980.

CARVALHO, A.; DE NEGRI, J. A. Estimação de equações de importação e exportação de produtos agropecuários para o Brasil (1977/1998). Rio de Janeiro: IPEA, jan. 2000. (Texto para discussão n. 698.)

CASTILHO, M. R. Acordo de Livre Comércio com a UE: a vulnerabilidade dos produtos industriais produzidos pelo Mercosul à competição europeia. Nova Economia, v. 15, n. 2, 2009. 
CASTILHO, M. R.; LUPORINI, V. A Elasticidade-renda do comércio regional de produtos manufaturados. In: XXXVII ANPEC, Foz do Iguaçu, PR, 2009. Anais...

CASTRO, A. S; CAVALCANTI, M. A. Estimação de equações de exportação e importação para o Brasil - 1955/95. Brasília: IPEA, mar. 1997. (Texto para discussão, n. 469.)

CAVALCANTI, M. H.; RIBEIRO, F. J. As exportações brasileiras no periodo 1977/1996: desempenho e determinantes. Rio de Janeiro: IPEA, 1998. 52 p. (Texto para discussão, n. 545.)

CHEUNG, Y. W.; SENGUPTA, R. Impact of Exchange Rate Movements on Exports: an Analysis of Indian Non-Financial Sector Firms. Bank of Finland, Discussion Paper, n. 10, 2013.

DICKEY, D.; FULLER, W. A. Distribution of the Estimates for Autoregressive Time Series with a Unit Root. Journal of the American Statistical Association, v. 74, n. 366a, p. 427-431, 1979.

ENDERS, W. Applied Econometric Time Series. 3. ed. Wiley Series in Probability and Statistics, 2010.

ENGLE, R. F.; GRANGER, C. J. Cointegration and Error Correction: Representation, Estimation and Testing. Econometrica, v. 55, n. 2, p. 251-276, 1987.

FEISTEL, P. R.; HIDALGO, A. B.; ZUCHETTO, F. B. Determinantes do intercâmbio comercial de produtos agrícolas entre Brasil e China: o caso da soja. Revista Análise Econômica. Porto Alegre, v. 33, n.63, p. 63-89, 2015.

FERREIRA, A. B. Funções de exportação do Brasil: estimativas para os principais mercados. Nova Economia, Belo Horizonte, v. 8, n. 1, p. 65-86, 1998.

FUNCEX. Fundação Centro de Estudos de Comércio Exterior. Base de Dados. Disponível em: < http://www.funcex.org.br/>. Acesso em: 11 jun. 2013.

GOLDSTEIN, M.; KHAN, M. S. The Supply and Demand for Exports: A Simultaneous Approach. The Review of Economics and Statistics, v. 60, p. 257-286, 1978.

GREENE, W. H. Econometric Analysis. $6^{\text {th }}$ ed. New Jersey: Prentice Hall, 2008. 1.216 p.

GUIMARÃES, E. A. et al. A. Índices de preço e quantum das exportações brasileiras. Funcex, 1997. (Texto para discussão, n. 121.)

HAMILTON, J. Time Series Analysis. $2^{\text {nd }}$ ed. New Jersey: Princeton University Press, 1994. 799 p.

IFS/IMF. International Financial Statistics/International Monetary Fund. Disponível em: <http:// www.imf.org/en/Data>. Accesso em: 10 mar. 2013.

JOHANSEN, S. Statistical Analysis of Cointegration Vector. Journal of Economic Dynamics and Control, v. 12, n. 2, p. 231-254, 1988.

JOHANSEN, S. Cointegration in Partial Systems and the Efficiency of Single-Equation Analysis. Journal of Econometrics, v. 52, n. 3, p. 389-402, 1992.

JOHANSEN, S.; JUSELIUS, K. Maximum Likelihood Estimation and Inference on Cointegration - With Application to the Demand of Money. Oxford Bulletin of Economics and Statistics, v. 52 , n. 2, p. 169-210, 1990.

JOHNSTON, J.; DINARDO, J. Métodos econométricos. 4. ed. Amadora, Portugal: McGraw-Hill, 2001.

KAWAMOTO, C. T.; SANTANA, B. L.; FONSECA, H. Elasticidade renda e elasticidade preço das exportações e das importações de produtos industrializados no Brasil (2003-2010): Uma avaliação utilizando dados em painel. Revista de Economia, v. 39, n. 2, p. 139-159, 2013. 
KWIATKOWSKI, D. et al. Testing the Null Hypothesis of Stationarity Against the Alternative of a Unit Root: How Sure Are We that Economic Time Series Have a Unit Root? Journal of Econometrics, v. 54, n. 1, p. 159-178, 1992.

MCKENZIE, M. D. The Impact of Exchange Rate Volatility on Australian Trade Flows. Journal of International Financial Markets, Institutions and Money, v. 8, n. 1, p. 21-38, 1998.

MDIC/SECEX. Ministério do Desenvolvimento da Indústria e Comércio Exterior. Secretaria de Comércio Exterior (Secex). Banco de Dados, 2013. Disponível em: <http://www.mdic. gov.br/>. Acesso em: 10 mar. 2013.

MEYER, T. R. Taxa de câmbio e exportações brasileiras: uma avaliação do período recente. 2008. 92 f. Dissertação (Mestrado) - Universidade do Estado do Rio de Janeiro, Rio de Janeiro, 2008.

MORTATTI, C. M.; MIRANDA, S. H. G. de; BACCHI, M. R. P. Determinantes do comércio Brasil-China de commodities e produtos industriais: uma aplicação VECM. Economia Aplicada, Ribeirão Preto, v. 15, n. 2, 2011.

OREIRO, J. L.; LEMOS, B. P.; DA SILVA, G. J. C. A relação entre a elasticidade-renda das exportações, a taxa de câmbio real e o hiato tecnológico: teoria e evidência. Economia \& Tecnologia, ano 3, v. 8, 2007.

PINTO, M. B. de P. O crescimento das exportações brasileiras de manufaturados 1954-1974. Estudos Econômicos, v. 10, n. 3, p. 101-143, 1980

PAIVA, C. Trade Elasticities and Market Expectations in Brazil. International Monetary Fund, IMF Institute, WP/03/140, 2003.

PERÉE, E.; STEINHERR, A. Exchange Rate Uncertainty and Foreign Trade. European Economic Review, v. 33, n. 6, p. 1241-1264, 1989.

PHILLIPS, P.; PERRON, P. Testing for a Unit Root in Time Series Regression. Biometrica, v. 75, n. 2, p. 335-346, 1988.

POON, W. C.; CHOONG, C. K.; HABIBULLAH, M. S. Exchange Rate Volatility and Exports for Selected East Asian Countries: Evidence from Error Correction Model. ASEAN Economic Bulletin, v. 22, n. 2, p. 144-159, 2005.

PORTUGAL, M. S. A instabilidade dos parâmetros nas equações de exportação brasileira. Pesquisa e Planejamento Econômico, v. 23, n. 2, p. 313-348, 1993.

POURCHET, H. Estimação de equações de exportação por setores: uma investigação do impacto do câmbio. 2003. 139 f. Dissertação (Mestrado em Engenharia Elétrica) - Pontifícia Universidade Católica do Rio de Janeiro, Rio de Janeiro, 2003.

RIBEIRO, L. S. L. Dois ensaios sobre a balança comercial. 2006. 148 f. Dissertação (Mestrado em Economia) - Pontifícia Universidade Católica do Rio de Janeiro, Rio de Janeiro, 2006.

SAUER, C.; BOHARA, A. Exchange Rate Volatility and Exports: Regional Differences between Developing and Industrialized Countries. Review of International Economics, v. 9, n. 1, p. 133-152, 2001.

UN COMTRADE. United Nations Commodity Trade System. Base de dados. Disponível em: $<$ http://comtrade.un.org >. Acesso em: 2013.

VERGIL, H. Exchange Rate Volatility in Turkey and its Effect on Trade Flows. Journal of Economic and Social Research, v. 4, n. 1, p. 83-99, 2002. 
ZINI, A. A. Funções de exportação e de importação para o Brasil. Pesquisa e Planejamento Econômico, Rio de Janeiro, v. 18, n. 3, p. 615-662, 1988.

\section{Sobre os autores}

Dieison Lenon Casagrande - dieisonlenon@yahoo.com.br Universidade Federal de Pernambuco, Recife, Pernambuco, Brasil. ORCID: https://orcid.org/0000-0003-4096-3971.

Paulo Ricardo Feistel_prfeistel@gmail.com

Universidade Federal de Santa Maria, Santa Maria, Rio Grande do Sul, Brasil. ORCID: https://orcid.org/0000-0002-6090-8278.

ÁlvaroBarrantes Hidalgo-abarrantes@uol.com.br

Universidade Federal de Pernambuco e Pesquisador do Conselho Nacional de Desenvolvimento Científico e Tecnológico, Recife, Pernambuco, Brasil.

ORCID: https://orcid.org/0000-0002-2087-6515.

André Filipe Zago de Azevedo - aazevedo@unisinos.br

Universidade do Vale do Rio dos Sinos, São Leopoldo, Rio Grande do Sul, Brasil.

ORCID: https://orcid.org/0000-0002-2745-0381.

Os autores agradecem as contribuições e comentários dos pareceristas anônimos desta revista. Os erros e omissões remanescentes são, naturalmente, de inteira responsabilidade dos autores.

\section{Sobre o artigo}

Recebido em 01 de outubro de 2015. Aprovado em 20 de junho de 2017. 